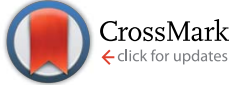

Cite this: RSC Adv., 2017, 7, 16730
Received 16th December 2016 Accepted 28th February 2017

DOI: 10.1039/c6ra28284a

rsc.li/rsc-advances

\title{
Turn-on fluorescent probes that can light up endogenous RNA in nucleoli and cytoplasm of living cells under a two-photon microscope $\uparrow$
}

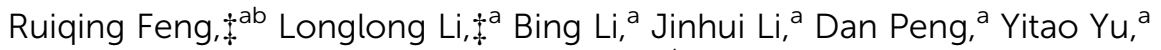 \\ Qiuhong Mu, ${ }^{a}$ Ning Zhao, ${ }^{* a}$ Xiaoqiang $\mathrm{Yu}^{\star b}$ and Zhenhua Wang*c
}

\begin{abstract}
We have synthesized two-photon organic molecule probes (IMT-E and IMT-M), which selectively stain endogenous RNA in the nucleolus and cytoplasm of living cells in a short incubation time. Using these probes, bright two-photon excitation fluorescence (TPEF) images of living cells have been developed. Titrations and digest tests of ribonuclease indicate the markedly higher affinity of these probes for RNA, especially when using IMT-E. Upon binding to RNA, the fluorescence intensity of IMT-E increases by about 15-fold, showing that IMT-E is a turn-on probe for the detection of RNAs. MTT assays demonstrate that the mitochondria of cells maintain their electron mediating ability after being stained with the probes. These results demonstrate that IMT-E is an attractive two-photon turn-on fluorescent probe for visualizing RNA in living cells.
\end{abstract}

\section{Introduction}

Ribonucleic acid (RNA) plays an active role within living cells by catalyzing biological reactions, controlling gene expression, and sensing and communicating responses to cellular signals. ${ }^{\mathbf{1 - 4}}$ Recently, researchers have found that the variations in nucleolus morphology are closely associated with disease phenotypes, and the relationship between the morphology of the nucleolus and cancerous status in tumor cells has attracted increasing attention., ${ }^{5,6}$ As is known, RNA is mainly distributed in the nucleolus and cytoplasm of living cells, and the nucleolus is the key site in the nucleus that synthesizes and assembles ribosomal RNAs (rRNA). ${ }^{7}$ Therefore, gaining a better understanding of the morphology of the nucleolus using RNA imaging in living cells could offer powerful help for the advancement of molecular biology, pathophysiology, and medical diagnostics. ${ }^{8-11}$ As one of the most powerful techniques for monitoring biomolecules in living systems, fluorescence imaging techniques are widely used to visualize morphological details of RNA in living cells. ${ }^{12}$ Consequently, it is significant

${ }^{a}$ Shandong Key Laboratory for Adhesive Materials, Advanced Materials Institute, Shandong Academy of Sciences, Jinan 250014, Shandong, P. R. China. E-mail: zhaon@sdas.org

${ }^{b}$ Center of Bio \& Micro/Nano Functional Materials, State Key Laboratory of Crystal Materials, Shandong University, Jinan 250100, P. R. China. E-mail: yuxq@sdu.edu. cn; Tel: +8653188366418

${ }^{c}$ Shandong Analysis and Testing Center, Shandong Academy of Science, Jinan 250014, Shandong, P. R. China. E-mail: wzh312@mail.sdu.edu.cn

$\dagger$ Electronic supplementary information (ESI) available. See DOI: $10.1039 /$ c6ra28284a

$\ddagger$ Feng and Li made equal contributions to this work. and essential to design and develop RNA fluorescent probes for imaging the nucleolus of living cells.

In the field of fluorescent probes for bio-imaging, twophoton turn-on fluorescence probes have gained tremendous attention. ${ }^{13}$ This is because two-photon fluorescence microscopy (TPM) has unique merits in imaging living specimen, such as high detection sensitivity, deep penetration, no image distortion, low photodamage and reduced photobleaching. ${ }^{14-17}$ Moreover, turn-on probes possess the advantages of low background noise and high sensitivity when binding to biomolecules. ${ }^{18}$ For imaging nucleolus RNA in living cells, the probe not only needs to penetrate the cell membrane, but also enter the nucleus. Thus, RNA probes have a high requirement for membrane permeability. Generally, large conjugated structures could help probes to achieve better two-photon properties. ${ }^{\mathbf{1 9 , 2 0}}$ However, it is a contradiction that increasing the conjugate structure could reduce the membrane permeability. ${ }^{21}$ Recently, small-molecule fluorescent probes have become the most practical tool for imaging living cells, due to their good membrane permeability and chemical tractability.$^{22}$ However, it is rather difficult to design small-molecule fluorescent probes with excellent two-photon properties and membrane permeability at the same time. In the field of two-photon probes for RNA detection, an appropriate probe is rarely available. Ohulchanskyy et al. found that the conventional nucleic acid dye cyan 40 can be used to image RNA in nucleoli using TPM. However, the two-photon action absorption cross section $(\delta \times$ $\Phi)$ of the probe, a crucial parameter for TPEF probes, was not reported. ${ }^{23}$ Saini et al. synthesized a new trivalent aluminium metal complex (1) which could achieve nucleolus imaging in a variety of cell lines, but its two-photon properties were not 
reported. ${ }^{24}$ Our research group has also reported several carbazole- and indole-based two-photon RNA probes for cell imaging. ${ }^{25,26}$ However, because of the poor membrane permeability, living cell imaging using these probes is limited. Subsequently, in order to improve the permeability, we introduced a long alkyl chain into indole-based di-cationic salts, and synthesized two RNA probes that can stain living cells and have two-photon properties. Unfortunately, the incubation time of 1.5 hours demonstrated that their permeability was still less than satisfactory. ${ }^{27}$ Only Guo et al. synthesized an indole-based cyanine complex as a two-photon RNA-selective probe that realized successful imaging in living cells. ${ }^{28}$ Therefore, it is a significant challenge to develop two-photon turn-on probes with good membrane permeability for imaging RNA in living cells.

According to a variety of theoretical and experimental data, the introduction of terminal donor (D) and acceptor (A) moieties into small $\pi$-conjugates can result in a considerable twophoton absorption cross section $(\delta)$ value and a simultaneous red shift in emission. ${ }^{20,29,30}$ Based on previous work, two-photon RNA probes with good membrane permeability may be obtained by using various cationic salts with a particular chemical structure by appropriately increasing the donor-acceptor strength and intramolecular conjugation length. In this paper, we introduced indole as a donor group and benzothiazole iodized salt as an acceptor group into $\pi$-conjugates, and prepared two mono-cationic compounds (IMT-E: $(E)-2-(2-(1 H-$ indol-3-yl)vinyl)-3-(2-hydroxyethyl)benzo[d]thiazol-3-ium, MW: 448; IMT-M: (E)-2-(2-(1H-indol-3-yl)vinyl)-3-methylbenzo[d] thiazol-3-ium, MW: 418, see Fig. 1). Because of their smaller molecular structures and the appropriate electron donating ability of indole and electron withdrawing ability of benzimidazole iodized salt, IMT-E and IMT-M may be two-photon probes with good membrane permeability for imaging nucleolus RNA in living cells.

The subsequent testing of IMT-E and IMT-M gave us a pleasant surprise. The probes were found to possess a twophoton property, and can light up the RNA in the nucleolus and cytoplasm of living cells with excellent biological compatibility. After binding to RNA, the fluorescence intensity from IMT-E/IMT-M increased by about 15/10-fold, showing that the dyes are turn-on probes for the detection of RNAs.

\section{Experimental}

\section{Synthesis}

The synthetic details for IMT-E and IMT-M are shown in Scheme 1 and the ESI. $\dagger$ The dyes were synthesized via Knoevenagel condensation reactions between $N$-methyl-2methylbenzothiazole iodine and 4-dimethylaminobenzaldehyde, using piperidine as the catalyst.

IMT-E. ${ }^{1} \mathrm{H}$ NMR (400 MHz): $12.478(\mathrm{~s}, 1 \mathrm{H}), 8.448(\mathrm{t}, J=7.66$, $2 \mathrm{H}), 8.342(\mathrm{~d}, J=7.96,1 \mathrm{H}), 8.205(\mathrm{~d}, J=4.96,1 \mathrm{H}), 8.16(\mathrm{t}, J=$ $9.72,1 \mathrm{H}), 7.798(\mathrm{t}, J=7.76,1 \mathrm{H}), 7.713(\mathrm{q}, J=9.29,1 \mathrm{H}), 7.604(\mathrm{t}, J$ $=5.4,2 \mathrm{H}), 7.357(\mathrm{~d}, J=4.36,2 \mathrm{H}), 5.261(\mathrm{t}, J=5.68,1 \mathrm{H}), 4.959(\mathrm{t}$, $J=4.34,2 \mathrm{H}), 3.965$ (q, $J=4.88,2 \mathrm{H}) .{ }^{13} \mathrm{C}$ NMR (400 MHz, DMSO$\left.d_{6}\right), \delta$ (ppm): 173.40, 144.44, 142.06, 138.38, 137.87, 129.23,
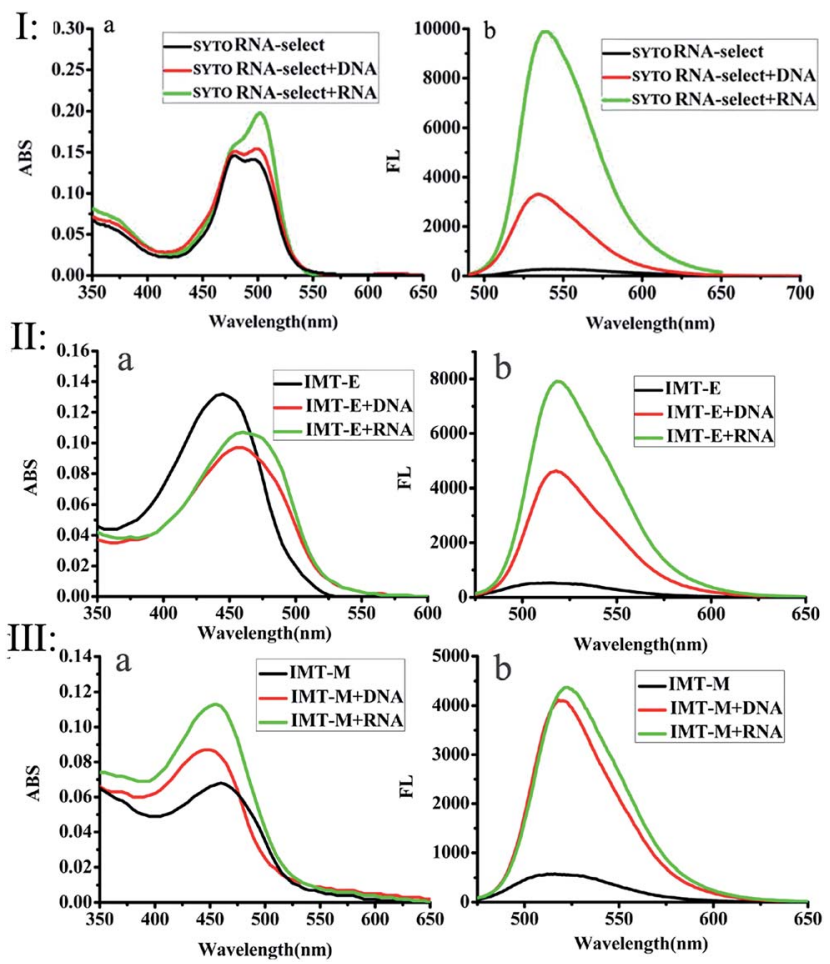

Fig. 1 The UV-vis absorption (a) and single-photon excited fluorescence (b) spectra of SYTO RNA-Select (I), IMT-E (II) and IMT-M (III) in buffer, RNA solutions and DNA solutions. Buffer: $10 \mathrm{mM}$ Tris $-\mathrm{HCl}$, $100 \mathrm{mM} \mathrm{KCl}, \mathrm{pH}=7.2$. Compound concentration: $2 \times 10^{-6} \mathrm{~mol} \mathrm{~L}^{-1}$. Excitation at each largest single-photon absorption wavelength. Ratio (phosphate of NA/dye): 300:1 for SYTO RNA-Select (I), $500: 1$ for IMT-E and IMT-M.

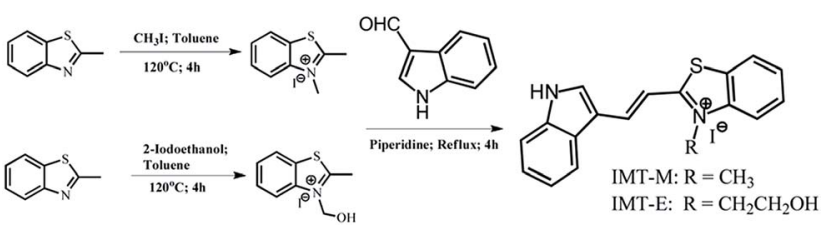

Scheme 1 The synthesis of IMT-E and IMT-M.

127.81, 127.27, 125.17, 124.37, 124.31, 122.89, 121.31, 116.72, 114.68, 113.62, 107.11. HRMS $(\mathrm{m} / \mathrm{z}):[\mathrm{M}-\mathrm{I}]^{+}$. Calcd for $\mathrm{C}_{19} \mathrm{H}_{17} \mathrm{~N}_{2} \mathrm{OS}$, 321.1; found, 321.42 .

IMT-M. ${ }^{1} \mathrm{H}$ NMR (400 MHz): $12.497(\mathrm{~s}, 1 \mathrm{H}), 8.466(\mathrm{t}, J=10.6$, $2 \mathrm{H}), 8.335(\mathrm{~d}, J=8,1 \mathrm{H}), 8.275(\mathrm{t}, J=4.42,1 \mathrm{H}), 8.149(\mathrm{~d}, J=8.36$, $1 \mathrm{H}), 7.815(\mathrm{t}, J=7.72,1 \mathrm{H}), 7.712(\mathrm{t}, J=7.64,1 \mathrm{H}), 7.595(\mathrm{t}, J=$ $4.5,1 \mathrm{H}), 7.525(\mathrm{~d}, J=15.76,1 \mathrm{H}), 7.525(\mathrm{~d}, J=15.76,1 \mathrm{H}), 7.370-$ $7.324(\mathrm{~m}, 2 \mathrm{H}), 4.277(\mathrm{~s}, 3 \mathrm{H}) .{ }^{13} \mathrm{C}$ NMR (400 MHz, DMSO- $d_{6}$ ), $\delta$ (ppm): 172.45, 144.73, 142.41, 138.37, 138.04, 129.31, 127.09, $125.20,124.40,124.30,122.90,121.48,116.40,114.70,113.62$, 106.22. HRMS $(m / z):[M-I]^{+}$. Calcd for $\mathrm{C}_{18} \mathrm{H}_{15} \mathrm{~N}_{2} \mathrm{~S}, 291.1$; found, 291.39.

\section{Reagents and chemicals}

Indole was purchased from J\&K Chemical (Beijing, China). Iodomethane, iodoethanol and 2-aminobenzimidazole were 
purchased from Aladdin Co. All other chemicals were from commercial sources and of analytical reagent grade, unless indicated otherwise. Ultrapure water was used throughout. Calf thymus DNA and E. coli RNA, used as the models for DNA and RNA, and ribonuclease A (RNase) were obtained from Sigma. Tris and PBS were purchased from Seikagaku Corporation (Japan).

\section{Apparatus and general methods}

Nuclear magnetic resonance spectra $\left({ }^{1} \mathrm{H}\right.$ and $\left.{ }^{13} \mathrm{C}\right)$ were obtained on a Bruker Avance 400 spectrometer. The HRMS spectra were recorded on an Agilent Technologies 6510 Q-TOF LC/MS. The UV-visible-near-IR absorption spectra of dilute solutions were recorded on a HITACHI U-2910 spectrophotometer using a quartz cuvette with a path length of $1 \mathrm{~cm}$. One-photon fluorescence spectra were obtained on a HITACHI F-2700 spectrofluorimeter equipped with a $450 \mathrm{~W}$ Xe lamp. TPEF was measured on a SpectroPro300i and the pump laser beam came from a mode-locked Ti:sapphire laser system with a pulse duration of $220 \mathrm{fs}$, and a repetition rate of $76 \mathrm{MHz}$ (Coherent Mira900-D). PBS buffer solution (137 mM NaCl, $2.7 \mathrm{mM} \mathrm{KCl,} 10$ $\left.\mathrm{mM} \mathrm{Na} 2 \mathrm{HPO}_{4} \cdot 12 \mathrm{H}_{2} \mathrm{O}, 2 \mathrm{mM} \mathrm{NaH} \mathrm{PO}_{4} \cdot 2 \mathrm{H}_{2} \mathrm{O}, \mathrm{pH}=7.40\right)$ and Tris-HCl buffer solution ( $10 \mathrm{mM}$ Tris, $100 \mathrm{mM} \mathrm{KCl,} \mathrm{pH}=7.2$ ) were used. All pH measurements were performed with a METTLER TOLEDO FE20-FiveEasy ${ }^{\mathrm{TM}}$ pH-meter. Cell viability was assayed using a cell proliferation Kit I, with the $492 \mathrm{~nm}$ absorbance being detected using a PerkinElmer Victor plate reader. Two-photon fluorescence images were obtained using a IX71 (Olympus) multiphoton laser scanning microscope with a Coherent Mira900-D. The dyeing rate experiment was carried out using flow cytometry (ImageStreamX MarkII). The data were obtained using INSPIRE software and analyzed using IDEAS Application v6.0 software.

\section{Spectroscopic measurements}

The fluorescence quantum yields $(\Phi)$ can be calculated using eqn (1):

$$
\Phi_{\mathrm{s}}=\Phi_{\mathrm{r}} \frac{A_{\mathrm{r}}}{A_{\mathrm{s}}} \frac{\lambda_{\mathrm{r}}}{\lambda_{\mathrm{s}}} \frac{n_{\mathrm{s}}{ }^{2}}{n_{\mathrm{r}}{ }^{2}} \frac{F_{\mathrm{s}}}{F_{\mathrm{r}}}
$$

where the subscripts $s$ and $r$ refer to the sample and the reference materials, respectively. $\Phi$ is the quantum yield, $F$ is the integrated emission intensity, $A$ stands for the absorbance, and $n$ is the refractive index. In this paper, the quantum yield was calculated by using fluorescein in aqueous $\mathrm{NaOH}(\mathrm{pH}=13, \Phi=$ $0.95)$ as a standard. ${ }^{31}$

Two-photon absorption (TPA) cross sections were measured using the two-photon induced fluorescence method. Rhodamine $\mathrm{B}$ in $\mathrm{MeOH}(\delta=210 \mathrm{GM})$ was used as the standard, ${ }^{32}$ whose two-photon properties have been reported in the literature, and thus, cross sections can be calculated using eqn (2):

$$
\delta_{\mathrm{s}}=\delta_{\mathrm{r}} \frac{\Phi_{\mathrm{r}}}{\Phi_{\mathrm{s}}} \frac{C_{\mathrm{r}}}{C_{\mathrm{s}}} \frac{n_{\mathrm{s}}}{n_{\mathrm{r}}} \frac{F_{\mathrm{s}}}{F_{\mathrm{r}}}
$$

where the subscripts s and $r$ refer to the sample and the reference materials, respectively. $\delta$ is the TPA cross-section value, $C$ is the concentration of the solution, $n$ is the refractive index of the solution, $F$ is the two-photon excited fluorescence integral intensity and $\Phi$ is the fluorescence quantum yield.

\section{Cell culture and staining}

Human cervical cancer cell lines (HeLa) were cultured in Dulbecco's modified Eagle's medium supplemented with penicillin/streptomycin and $10 \%$ bovine calf serum in a $5 \% \mathrm{CO}_{2}$ incubator at $37{ }^{\circ} \mathrm{C}$. IMT-E/IMT-M were dissolved in DMSO at a concentration of $1 \mathrm{mM}$.

For living cell staining experiments, cultured cells grown on glass coverslips were stained with $5 \mu$ M IMT-E/IMT-M in culture medium for $30 \mathrm{~min}$ at $37^{\circ} \mathrm{C}$ and then imaged using fluorescence microscopy.

For fixed cell staining experiments, cultured cells grown on glass coverslips were pretreated according to the following procedure: cells were first fixed by $4 \%$ paraformaldehyde for $30 \mathrm{~min}$ or pre-chilled methanol $\left(-20{ }^{\circ} \mathrm{C}\right)$ for $15 \mathrm{~min}$ and were then permeabilized by $0.5 \%$ Triton $\mathrm{X}-100$ for $2 \mathrm{~min}$ at ambient temperature.

For the RNase digest test, two sets of prefixed HeLa cells were stained with $5 \mu \mathrm{M}$ IMT-E/IMT-M in PBS ( $\mathrm{pH}=7.4$ ) for $30 \mathrm{~min}$. After rinsing with PBS twice, a total of $1 \mathrm{~mL}$ PBS (as a control experiment) was added to one group of cells and $25 \mathrm{mg} \mathrm{mL}^{-1}$ DNase-free RNase (GE) was added to the other group of cells. Then the two sets of cells were incubated at $37{ }^{\circ} \mathrm{C}$ in $5 \% \mathrm{CO}_{2}$ for 2 h. After rinsing with PBS twice, both two sets of cells were imaged using wide-field fluorescence microscopy.

Cell-viability assay. The study of the effect of IMT-E/IMT-M on cell viability was carried out using the methylthiazolyldiphenyltetrazolium bromide (MTT) assay. HeLa cells growing in log phase were seeded into 96-well plates $\left(\mathrm{ca} .1 \times 10^{4}\right.$ cells per well) and were allowed to adhere for $24 \mathrm{~h}$. For examining short-term cytotoxic effects, IMT-E/IMT-M $(100 \mu \mathrm{L}$ per well $)$ at a concentration of $5 \mu \mathrm{M}$ was added into the wells of the treatment group, and $100 \mu \mathrm{L}$ per well DMSO diluted in DMEM at a final concentration of $0.2 \%$ was added to the negative control group. The cells were then incubated for $2,4,8,12$ and $24 \mathrm{~h}$ at $37^{\circ} \mathrm{C}$ under $5 \% \mathrm{CO}_{2}$, and then the MTT assay was used as described. Each individual cytotoxic experiment was repeated three times.

\section{Fluorescence imaging}

Wide-field fluorescence microscopy images were acquired with an Olympus IX71 inverted microscope coupled with a CCD and display controller software. A confocal microscopic image and differential interference contrast (DIC) image were taken with a $488 \mathrm{~nm}$ Argon laser on an Olympus IX71 confocal microscope. TPEF imaging was obtained using an Olympus FV 300 Laser Confocal Microscope. In the two-photon experiments, the excitation wavelength was $800 \mathrm{~nm}$ from a Ti:sapphire femtosecond laser source (Coherent Chamelon Ultra). The incident power on the samples was modified by means of an attenuator and the samples were examined using a Power Monitor (Coherent). A multiphoton emission filter (FF01-750; Semrock) was used to block the IR laser. The differential interference contrast (DIC) images were taken with a $488 \mathrm{~nm}$ Ar ion laser. 


\section{Results and discussion}

\section{Photophysical properties of IMT-E/IMT-M}

The photophysical properties of IMT-E/IMT-M in different solvents at room temperature were measured, as shown in Fig. S1. $\uparrow$ Their one-photon absorption wavelengths in various solvents are similar, mainly in the range of 350-525 $\mathrm{nm}$. Furthermore, these probes have appropriate molar extinction coefficients $\left(\varepsilon: 6.62 \times 10^{4} \mathrm{~cm}^{-1} \mathrm{M}^{-1}\right.$ for IMT-E and $3.39 \times 10^{4}$ $\mathrm{cm}^{-1} \mathbf{M}^{-1}$ for IMT-M in PBS), making them suitable for imaging applications. In addition, the emission maximum of the two probes in these solvents was around $520 \mathrm{~nm}$. Such longwavelength emission is also approved for cellular imaging, to efficiently avoid the background fluorescence of endogenous fluorophores.

Subsequently, the photophysical properties of IMT-E/IMT$\mathbf{M}$ in the presence of DNA and RNA were carefully studied (Fig. 1 and Table 1). In order to make an intuitive comparison, the commercial RNA stain "SYTO RNA-Select" was also studied. In the absorption and emission spectra, IMT-E and IMT-M display a tiny shift (Fig. 1a) when binding to DNA or RNA, while their emission fluorescence intensities show a large change. IMT-E and IMT-M are weakly fluorescent in Tris-HCl buffer, whereas their fluorescence intensities show an approximately 15-fold (IMT-E) and 10-fold (IMT-M) enhancement in the presence of RNA, and a 10-fold (IMT-E) and 10-fold (IMT-M) enhancement in the presence of DNA (Fig. 1b). As shown in Table 1, in Tris-HCl buffer, the fluorescence quantum yields $(\Phi)$ of IMT-E and IMT-M are $0.062 \%$ and $0.031 \%$, but the values increase to $6.157 \%$ and $2.476 \%$ in the presence of RNA, respectively. The "turn-on" behaviors are similar to commercial SYTO RNA-Select (RNA: 35-fold, DNA: 12-fold). The obvious "turn-on" behavior can be attributed to the restraining of intramolecular motions when binding to DNA and RNA. Furthermore, as shown in Fig. 2, the TPEF properties of these dyes give rather similar results with excitation at $800 \mathrm{~nm}$, an optimal excitation wavelength provided by a commercial Ti:sapphire laser source. The probes exhibit much brighter two-photon excited fluorescence in the presence of RNA, than that in the presence of DNA. The $\delta \times \Phi$ values of IMT-E and IMT-M in buffer are 0.07 GM and 0.04 GM,
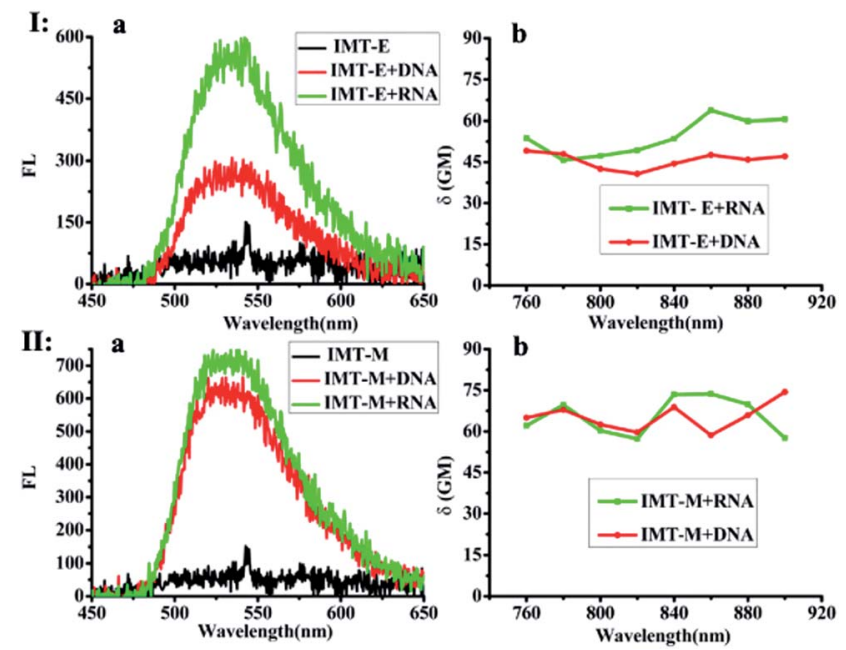

Fig. 2 Two-photon excited fluorescence spectra (excitation wavelength: $800 \mathrm{~nm}$ ) of IMT-E (la) and IMT-M (Ila), in the absence and presence of RNA or DNA (error limit: $8 \%$ ). The $\delta \times \Phi$ values at different wavelengths of IMT-E (Ib) and IMT-M (IIb) in the presence of RNA and DNA (error limit: 20\%). Buffer: $10 \mathrm{mM}$ Tris $-\mathrm{HCl}, 100 \mathrm{mM} \mathrm{KCl}, \mathrm{pH}=7.2$. Compound concentration: $2 \times 10^{-6} \mathrm{~mol} \mathrm{~L}^{-1}$. Ratio (phosphate of NA/ dye): $500: 1$ for IMT-E and IMT-M.

while in the presence of RNA, they increase to 5.95 GM and 4.9 GM (Table 1), respectively. The $\delta \times \Phi$ values at different wavelengths of the IMT-E and IMT-M in saturated RNA or DNA and Tris- $\mathrm{HCl}$ buffer are shown in Fig. 2b. From Table 1, the maximum $\delta$ values (in the presence of RNA) for IMT-E and IMT-M are 63.7 GM and 73.7 GM, respectively. These results indicate that these dyes show higher fluorescence responses to RNA than to DNA. It is expected that the compounds prefer to bind to RNA over DNA when entering cells. In addition, in the intracellular environment, acid compartments such as lysosomes change the intracellular $\mathrm{pH}$ dramatically. Therefore, the photophysical properties of an ideal probe in various intracellular environments should be stable. As shown in Fig. S2, $\dagger$ the peak positions of the fluorescence spectra of IMT$\mathbf{E}$ and IMT-M at different pH values are unchanged, and their fluorescence intensities also show very little change. This finding demonstrates an important advantage.

Table 1 The photophysical properties of IMT-E and IMT-M ${ }^{a}$

\begin{tabular}{|c|c|c|c|c|c|c|c|c|}
\hline Sample & Solvent & $\lambda_{1} / \mathrm{nm}$ & $\lambda_{2} / \mathrm{nm}$ & $\lambda_{3} / \mathrm{nm}$ & $\varepsilon / \mathrm{M}^{-1} \mathrm{~cm}^{-1}$ & $\Phi / \%$ & $\delta / \mathrm{GM}$ & $\delta \times \Phi / \mathrm{GM}$ \\
\hline \multirow[t]{3}{*}{ IMT-E } & Tris & 446 & 517 & 543 & $6.62 \times 10^{4}$ & 0.177 & 39.5 & 0.07 \\
\hline & DNA & 460 & 519 & 533 & $4.83 \times 10^{4}$ & 5.691 & 49.1 & 2.79 \\
\hline & RNA & 465 & 522 & 534 & $5.34 \times 10^{4}$ & 9.334 & 63.7 & 5.95 \\
\hline \multirow[t]{3}{*}{ IMT-M } & Tris & 460 & 520 & 541 & $3.39 \times 10^{4}$ & 0.092 & 47.6 & 0.04 \\
\hline & DNA & 447 & 518 & 535 & $4.39 \times 10^{4}$ & 6.151 & 74.4 & 4.58 \\
\hline & RNA & 453 & 517 & 534 & $4.54 \times 10^{4}$ & 5.481 & 73.7 & 4.90 \\
\hline
\end{tabular}

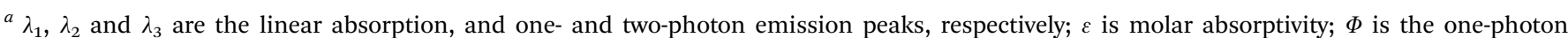

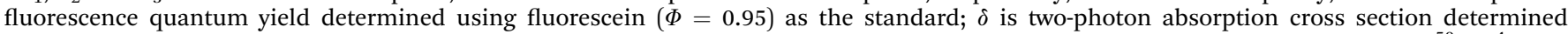

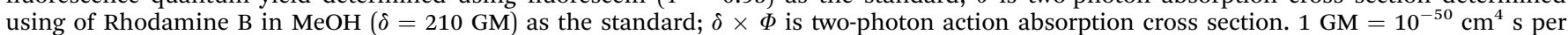

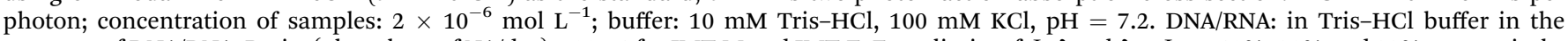

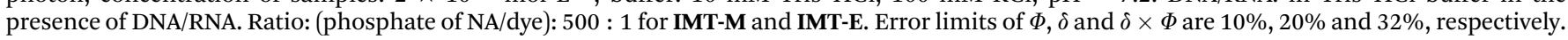




\section{RNA titrations}

In order to further study the RNA binding characteristics of these dyes and check for the possibility of using them as RNA probes, fluorescence titration experiments of SYTO RNA-Select, IMT-E and IMT-M (Fig. 3) were carried out to further study the RNA binding characteristics. Two factors can be used to explain the mechanism of the light-up effect upon binding to RNA. ${ }^{33,34}$ Firstly, the torsional motion of vinyl groups, which can result in rapid non-radiative decay in water, could be restricted by the steric effect derived from static interactions between the cationic benzothiazole and anionic phosphate of nucleic acids, therefore, the fluorescence of the probes increased significantly. Secondly, intramolecular charge transfer (ICT) can occur between the electron donor of the indole moiety and the electron acceptor of the benzothiazole cation. In water, the larger dipole moment in the excited state than that in the ground state interacts strongly with the polar solvent, which could lead to charge separation and result in the formation of a twist intramolecular charge transfer (TICT) state. When the dyes are protected from water in the grooves of RNA, the formation of a TICT state is restricted, and dyes become brightly luminescent.

More importantly, in Fig. 3, the fluorescence intensity evidently increases with the addition of RNA (especially the IMT-E probe). As shown in Table 1 , the enhancement of $\delta \times \Phi$ induced by RNA causes this value to increase by about 100 -fold. The saturation ratios ([RNA] : [dye]) for SYTO RNA-Select, IMT-E and IMT-M are $300: 1,500: 1$ and $500: 1$, respectively (Fig. 3).
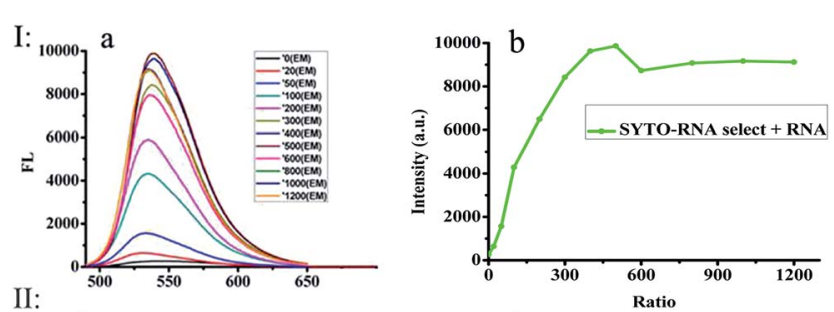

II:
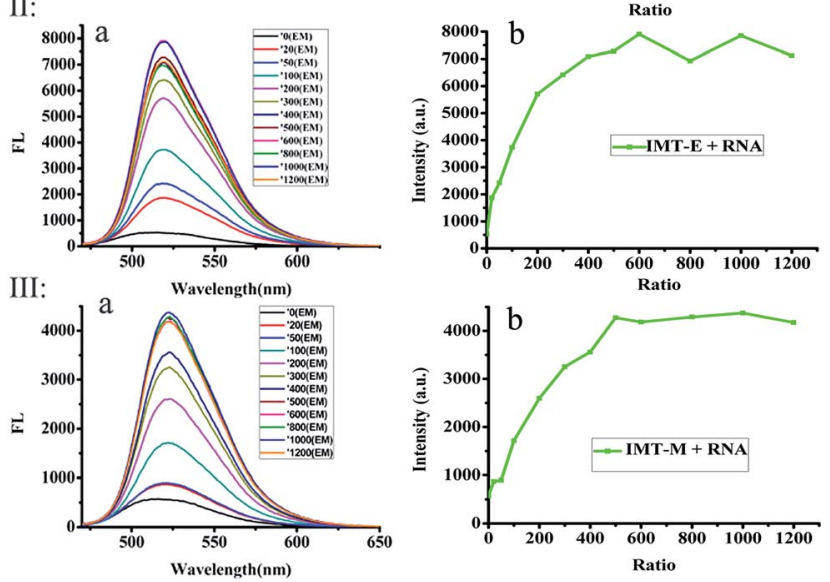

Fig. 3 Fluorescence titration spectra of SYTO RNA-Select (Ib), IMT-E (IIb) and IMT-M (IIIb) with the addition of different amounts of RNA; fluorescence intensity versus the [NA]/[dyes] ratio from 0 to $1200: 1$. Each point shown in (b) has an error of $10 \%$. Corresponding fluorescent spectra of the dyes with RNA (la, Ila and IIla). Excitation at each largest single-photon absorption wavelength; compound concentration: $2 \times 10^{-6} \mathrm{~mol} \mathrm{~L}^{-1}$.
These results indicate that IMT-E prefers RNA, and its sensitivity is similar to the commercial probe SYTO RNA-Select. Thus, IMT-E should be a good RNA probe.

\section{TPEF/OPEF imaging}

To demonstrate the permeability and one-photon imaging ability of IMT-E and IMT-M, cell imaging was performed using HeLa cells under a confocal microscope. The cells were incubated in culture medium with $5 \mu \mathrm{M}$ of IMT-E or IMT-M for about $30 \mathrm{~min}$ before the imaging experiments. Using flow cytometry experiments it can be seen that the dyeing rates of IMT-E and IMT-M are 99.8 and $96.4 \%$ respectively (Fig. S3†). Thus, the two dyes show an excellent staining effect. As shown in Fig. 4(I and II), cells incubated with these probes show intense fluorescence inside the cytoplasm and nucleolus, while no fluorescence is found in the extracellular spaces. These results imply that these probes exhibit suitable permeability to plasma membranes, and entrance into the HeLa cells is enabled through simple incubation. Meanwhile, the bright intracellular fluorescence also proves that the probes can maintain their good optical properties when staining cells.

After this experiment, TPEF images were also captured to examine the intracellular performance of these probes, as shown in Fig. 4(III and IV). The TPEF images, DIC pictures and

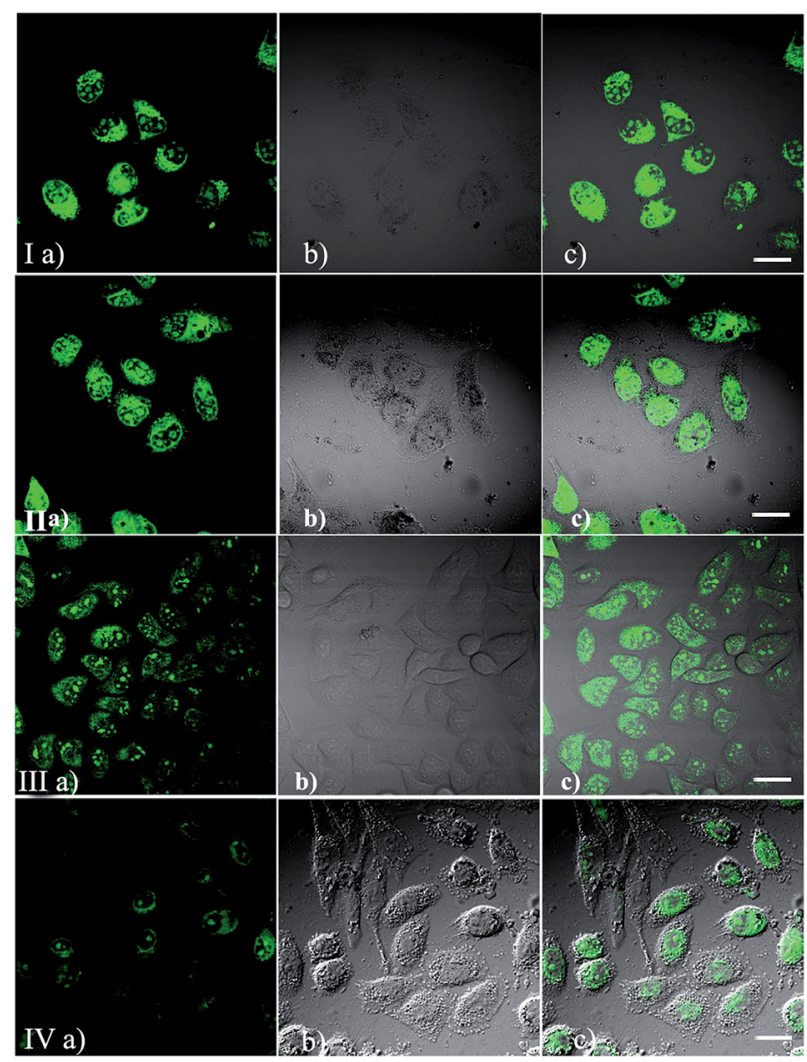

Fig. 4 Confocal fluorescence (I and II) and TPEF (III and IV) images of HeLa cells stained with IMT-E and IMT-M ( $5 \mu \mathrm{M}, 30$ min). (a) Fluorescent images; (b) DIC pictures; (c) overlay images of (a) and (b). (I-II) $\lambda_{\text {ex }}$ $=488 \mathrm{~nm}, \lambda_{\mathrm{em}}>565 \mathrm{~nm}$. (III-IV) $\lambda_{\mathrm{ex}}=800 \mathrm{~nm}, \lambda_{\mathrm{em}}<720 \mathrm{~nm}$. Bar $=20$ $\mu \mathrm{m}$. 
merged images clearly demonstrate that cells stained with IMTE and IMT-M show bright intracellular cytoplasma and nucleolus fluorescence when excited with $800 \mathrm{~nm}$, a commonly used wavelength for TPM.

\section{The RNase digest experiment}

As we all know, the nucleolus contains abundant proteins and RNAs, especially ribosomal proteins and rRNA. To further confirm the selectivity of the dyes for RNA, a digest test of ribonuclease (RNase), which only hydrolyzes the RNA in the cell and does not influence the DNA and proteins, was performed (Fig. 5). Fixed-permeabilized HeLa cells (Fig. 5a) were used in this experiment. After treatment with RNase, the fluorescence in the cytoplasm and nucleoli dramatically diminished and tended to redistribute to the nucleus (Fig. $5 \mathrm{c}$ and d) in contrast to the untreated sample (Fig. 5a and b). The above results reconfirm that these probes prefer RNA to DNA in the complex internal environment of cells, although there was an interaction between these probes and NA in the solution fluorescence measurements (Fig. 2 and 3). This puzzling state is possibly due to the difference between the structure of RNA/DNA in vitro and their real states in cells. It may also be influenced by the specific interaction between the different probes and nucleic acid.

\section{Cytotoxicity of IMT-E and IMT-M}

The cytotoxicity of IMT-E and IMT-M was also evaluated in HeLa cells using MTT assays. The cell viability assay data from HeLa cells treated with $5 \mu \mathrm{M}$ IMT-E and IMT-M during different incubation time were quantified (Fig. 6). HeLa cells showed $>70 \%$ viability within 24 hours. Thus, under the conditions of short treatment time (30 $\mathrm{min})$ and at micromolar concentrations of IMT-E or IMT-M, these probes can be considered as having low cytotoxicity.
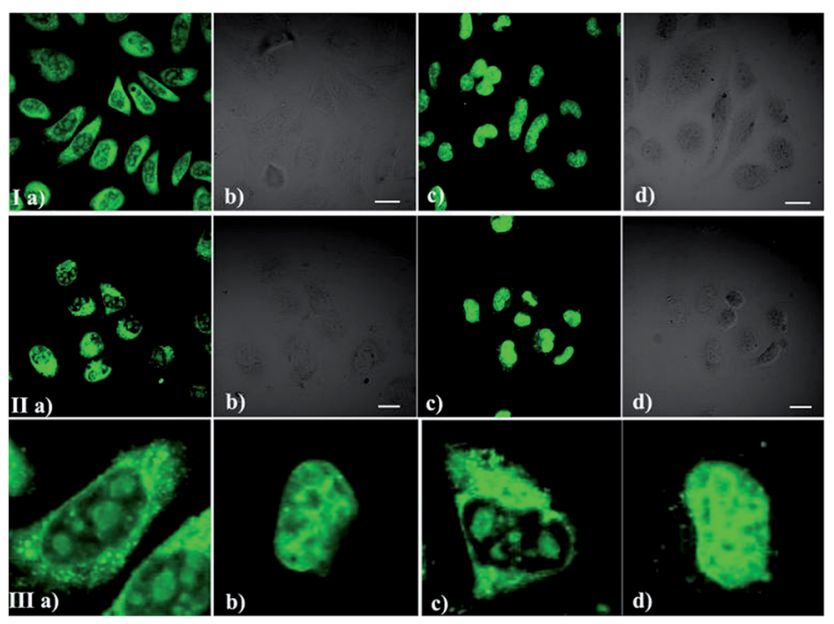

Fig. 5 The RNase digest experiment. Confocal fluorescence imaging of HeLa cells stained with IMT-E and IMT-M before (la and Ila) or after (Ic and IIC) treatment with RNase $\left(30 \mu \mathrm{g} \mathrm{mL}{ }^{-1}\right)$ for $2 \mathrm{~h}$ at $37^{\circ} \mathrm{C}$. (I/Ilb and I/IId) DIC pictures; (IIIa), (IIIb), (IIIC) and (IIId) are partial magnification images of (Ia), (IC), (Ila) and (IIC), respectively. Conditions: $5 \mu \mathrm{M}$ dyes; incubation time: $30 \mathrm{~min}$. Bar $=20 \mu \mathrm{m}$.

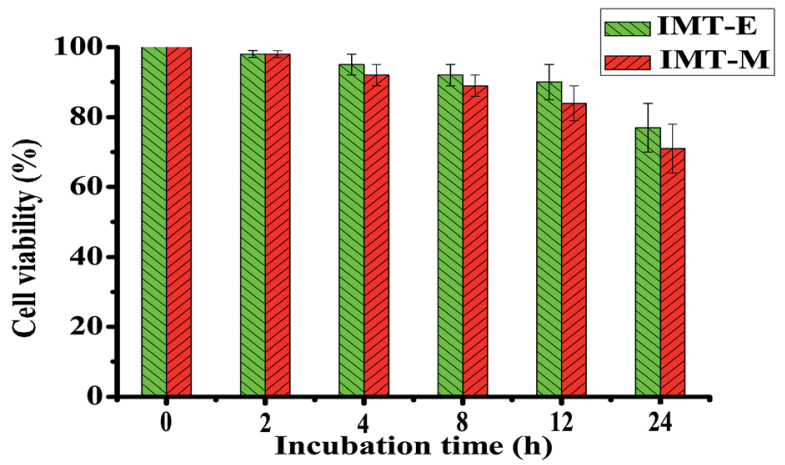

Fig. 6 MTT assay of HeLa cells treated with IMT-E/IMT-M (5 $\mu \mathrm{M})$ at different incubation times.

\section{Counterstain compatibility}

It is important to simultaneously stain one or more targets using two or more probes with different light-emitting ranges during cell imaging. Good compatibility of these RNA biosensors with other classic dyes would be helpful for these experiments. Particularly, good compatibility of RNA probes with the classic DNA-staining dye Hoechst 33342 can realize the imaging of DNA and RNA distribution simultaneously, probably revealing different patterns of RNA-DNA colocalization. From Fig. 7, it can be seen that IMT-E/IMT-M and Hoechst 33342 maintained their own labeling pattern and are not subject to any interference with each other during bioimaging. Therefore, IMT-E and IMT-M have good counterstain compatibility with Hoechst 33342 and are suitable for co-staining imaging.

\section{Photostability}

Photostability is one of the most important criteria for fluorescent imaging agents. Photostable fluorescent probes that can selectively illuminate cellular RNA are powerful tools for monitoring morphological changes in the nucleolus and studying these processes. Continuous scanning using a confocal microscope was used to quantitatively investigate the photostability of IMT-E, IMT-M and SYTO RNA-Select (Fig. 8).

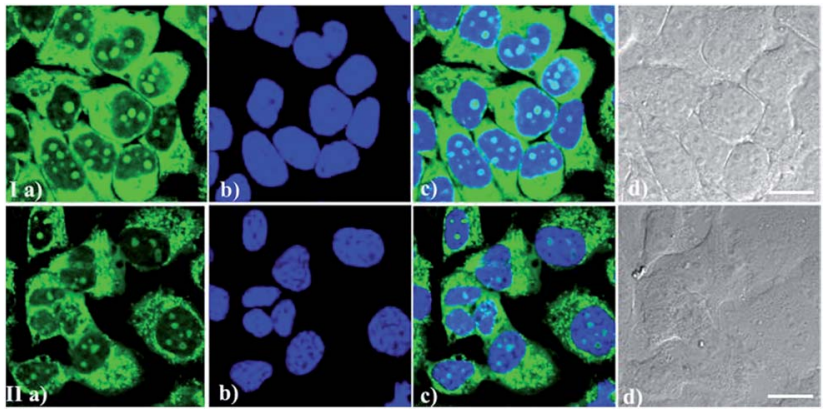

Fig. 7 Confocal fluorescence images of living HeLa cells stained with IMT-E/Hoechst 33342 (I) and IMT-M/Hoechst 33342 (II) in sequence. Each incubation time: $30 \mathrm{~min}$, concentration: $5 \mu \mathrm{M}$. (a) $\lambda_{\mathrm{ex}}=473 \mathrm{~nm}$, $\lambda_{\mathrm{em}}=500-550 \mathrm{~nm}$; (b) $\lambda_{\mathrm{ex}}=405 \mathrm{~nm}, \lambda_{\mathrm{em}}=435-465 \mathrm{~nm}$; (c) DIC picture; (d) overlay images of $(a-c)$. Bar $=20 \mu \mathrm{m}$. 

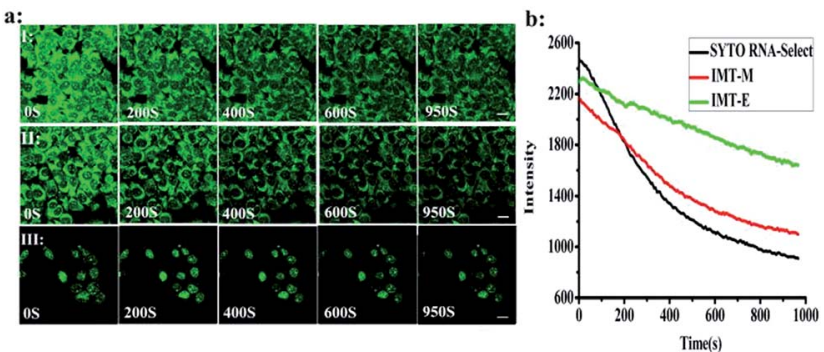

Fig. 8 Photostability of IMT-E, IMT-M and SYTO RNA-Select in confocal fluorescence microscopy imaging. (a) Confocal fluorescence microscopy images of the living HeLa cells incubated with IMT-E (I), IMT-M (II) and SYTO RNA-Select (III). (b) Quantitative analysis of the changes in the fluorescence intensities of IMT-E (green line), IMT-M (red line) and SYTO RNA-Select (black line). Each incubation time: $30 \mathrm{~min}$, concentration: $5 \mu \mathrm{M}$. $\lambda_{\mathrm{ex}}=473 \mathrm{~nm} ; \lambda_{\mathrm{em}}=500-600 \mathrm{~nm}$. Bar $=$ $20 \mu \mathrm{m}$.

Within $950 \mathrm{~s}$, IMT-E and IMT-M were still able to maintain a clear image, and the fluorescence signals of IMT-E and IMT-M decreased more slowly than SYTO RNA-Select. The results indicate that IMT-E and IMT-M display better photostability than SYTO RNA-Select.

\section{Conclusions}

In summary, we have presented two-photon turn-on probes (IMT-E and IMT-M) for imaging intracellular RNA distribution. The probes possess a "turn-on" effect when binding to RNA, and brightness TPEF images of living cells have been obtained. Moreover the probes possess low cytotoxicity, excellent membrane permeability, good photostability and the ability to light up RNA in the nucleolus and cytoplasm of living cells. In addition, these probes show good counterstain compatibility with Hoechst 33342, and are suitable for DNA-RNA colocalization experiments. Therefore, IMT-E and IMT-M should be appropriate RNA probes for imaging in living cells using TPM.

\section{Acknowledgements}

For financial support, we thank the National Natural Science Foundation of China (51303097 and 51273107), the Projects of National Natural Science Foundation of China (21277084), Natural Science Foundation of Shandong Province, China (ZR2012EMZ001), Open Project of State Key Laboratory for Supramolecular Structure and Materials (SKLSSM201524), and Shandong Province Key Research and Development Plan (2016GSF117015).

\section{Notes and references}

1 G. Bao, W. J. Rhee and A. Tsourkas, Annu. Rev. Biomed. Eng., 2009, 11, 25-47.

2 A. C. Peacock and C. W. Dingman, Biochemistry, 1968, 7, 668-674.

3 J. M. Chirgwin, A. E. Przybyla, R. J. MacDonald and W. J. Rutter, Biochemistry, 1979, 18, 5294-5299.

4 V. Glisin, R. Crkvenjakov and C. Byus, Biochemistry, 1974, 13, 2633-2637.
5 D. Zink, A. H. Fischer and J. A. Nickerson, Nat. Rev. Cancer, 2004, 4, 677-687.

6 A. I. Lamond and W. C. Earnshaw, Science, 1998, 280, 547-553.

7 M. Carmo-Fonseca, L. Mendes-Soares and I. Campos, Nat. Cell Biol., 2000, 2, E107-E112.

8 E. S. Lander, Nature, 2011, 470, 187-197.

9 N. N. Boustany, S. A. Boppart and V. Backman, Annu. Rev. Biomed. Eng., 2010, 12, 285.

10 L. Wei, Y. Shen, F. Xu, F. Hu, J. K. Harrington, K. L. Targoff and W. Min, ACS Chem. Biol., 2015, 10, 901-908.

11 A. J. Macario, Int. J. Clin. Lab. Res., 1995, 25, 59-70.

12 C. L. Evans and X. S. Xie, Annu. Rev. Anal. Chem., 2008, 1, 883-909.

13 L. Zeng, S. Chen, T. Xia, W. Hu, C. Li and Z. Liu, Anal. Chem., 2015, 87, 3004-3010.

14 P. T. So, C. Y. Dong, B. R. Masters and K. M. Berland, Annu. Rev. Biomed. Eng., 2000, 2, 399-429.

15 W. Denk, J. H. Strickler and W. W. Webb, Science, 1990, 248, 73-76.

16 B. R. Masters and P. T. So, Microsc. Res. Tech., 2004, 63, 3-11. 17 J. A. Feijó and N. Moreno, Protoplasma, 2004, 223, 1-32.

18 T. Terai and T. Nagano, Curr. Opin. Chem. Biol., 2008, 12, 515-521.

19 B. H. Cumpston, S. P. Ananthavel, S. Barlow, D. L. Dyer, J. E. Ehrlich, L. L. Erskine, A. A. Heikal, S. M. Kuebler, I. Y. S. Lee, D. McCord-Maughon, J. Qin, H. R. ckel, M. Rumi, X. Wu, S. R. Marder and J. W. Perry, Nature, 1999, 398, 51-53.

20 M. Pawlicki, H. A. Collins, R. G. Denning and H. L. nderson, Angew. Chem., Int. Ed., 2009, 48, 3244-3266.

21 H. Nikaido and M. Vaara, Microbiol. Rev., 1985, 49, 1-32.

22 H. M. Kim and B. R. Cho, Chem. Rev., 2015, 115, 5014-5055.

23 T. Y. Ohulchanskyy, H. E. Pudavar, S. M. Yarmoluk, V. M. Yashchuk, E. J. Bergey and P. N. Prasad, Photochem. Photobiol., 2003, 77, 138-145.

24 A. K. Saini, V. Sharma, P. Mathur and M. M. Shaikh, Sci. Rep., 2016, 6, 34807.

25 X. Liu, Y. Sun, Y. Zhang, F. Miao, G. Wang, H. Zhao, X. Yu, H. Liu and W. Y. Wong, Org. Biomol. Chem., 2011, 9, 3615-3618.

26 G. Song, F. Miao, Y. Sun, X. Yu, J. Z. Sun and W. Y. Wong, Sens. Actuators, B, 2012, 173, 329-337.

27 Y. Liu, W. Zhang, Y. Sun, G. Song, F. Miao, F. Guo, M. Tian, X. Yu and J. Sun, Dyes Pigm., 2014, 103, 191-201.

28 L. Guo, M. S. Chan, D. Xu, D. Y. Tam, F. Bolze, P. K. Lo and M. S. Wong, ACS Chem. Biol., 2015, 10, 1171-1175.

29 R. Kannan, G. S. He, L. Yuan, F. Xu, P. N. Prasad, A. G. Dombroskie and L. S. Tan, Chem. Mater., 2001, 13, 1896-1904.

30 R. Feng, Y. Sun, M. Tian, G. Zhang, R. Zhang, L. Guo and N. Zhao, J. Mater. Chem. B, 2015, 3, 8644-8649.

31 G. A. Crosby and J. N. Demas, Review, J. Phys. Chem., 1971, 75, 991-1024.

32 C. Xu and W. W. Webb, J. Opt. Soc. Am. B, 1996, 13, 481-491. 33 Y. Zhang, J. Wang, P. Jia, X. Yu, H. Liu, X. Liu and B. Huang, Org. Biomol. Chem., 2010, 8, 4582-4588.

34 H. Malak, F. N. Castellano, I. Gryczynski and J. R. Lakowicz, Biophys. Chem., 1997, 67, 35-41. 